\title{
Sierpinski carpet fractal monopole antenna for ultra-wideband applications
}

\author{
Medhal Bharathraj Kumar ${ }^{1}$, Praveen Jayappa ${ }^{2}$ \\ ${ }^{1}$ Department of Electronics and Communication Engineering, Shri Dharmasthala Manjunstheshwara Institute of Technology, Ujire, India \\ ${ }^{2}$ Department of Electronics and Communication Engineering, GM Institute of Technology, Davangere, India
}

\begin{tabular}{l} 
Article Info \\
\hline Article history: \\
Received Jan 29, 2021 \\
Revised Jul 4, 2021 \\
Accepted Jul 18, 2021 \\
\hline
\end{tabular}

Keywords:

Bandwidth

Fractal shape microstrip antenna

Microstrip line feed

Sierpinski carpet fractal monopole antenna

Ultra-wideband

\begin{abstract}
Microstrip antenna is broadly used in the modern communication system due to its significant features such as light weight, inexpensive, low profile, and ease of integration with radio frequency devices. The fractal shape is applied in antenna geometry to obtain the ultra-wideband antennas. In this paper, the sierpinski carpet fractal monopole antenna (SCFMA) is developed for base case, first iteration and second iteration to obtain the wideband based on its space filling and self-similar characteristics. The dimension of the monopole patch size is optimized to minimize the overall dimension of the fractal antenna. Moreover, the optimized planar structure is proposed using the microstrip line feed. The monopole antenna is mounted on the FR4 substrate with the thickness of $1.6 \mathrm{~mm}$ with loss tangent of 0.02 and relative permittivity of 4.4. The performance of this SCFMA is analyzed in terms of area, bandwidth, return loss, voltage standing wave ratio, radiation pattern and gain. The proposed fractal antenna achieves three different bandwidth ranges such as $2.6-4.0 \mathrm{GHz}, 2.5-4.3 \mathrm{GHz}$ and $2.4-4.4 \mathrm{GHz}$ for base case, first and second iteration respectively. The proposed SCFMA is compared with existing fractal antennas to prove the efficiency of the SCFMA design. The area of the SCFMA is $25 \times 20 \mathrm{~mm}^{2}$, which is less when compared to the existing fractal antennas.
\end{abstract}

This is an open access article under the CC BY-SA license.

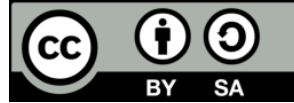

\section{Corresponding Author:}

Medhal Bharathraj Kumar

Department of Electronics and Communication Engineering, Shri Dharmasthala Manjunstheshwara Institute of Technology

Dharmasthala Rd, near Siddhavana, Ujire, Karnataka 574240, India

Email: bharathrajkumar100@gmail.com

\section{INTRODUCTION}

Nowadays, the wideband antennas are widely used as an enormous application in wireless communication systems due to its higher impedance bandwidth and simple structure [1]. Consequently, the ultra wideband (UWB) technology is considered as the significant solution for future wireless communication based on its huge frequency spectrum from $3.1 \mathrm{GHz}$ to $10.6 \mathrm{GHz}$ [2]-[4]. In developing the communication system, the antenna is required to be designed with less power consumption, inexpensive, low profile, lesser complexity, higher precision ranging, light weight, and ease of implementation [5]-[7]. The UWB technology is used in different applications such as high-accuracy radars, medical imaging systems, high-data rate wireless communications, remote sensing, medical monitoring, and medical sensor data collection systems [8]-[9]. These UWB antennas are constructed in different designs such as dipole and monopole/logarithmic antenna. In UWB applications, the monopole antennas are considered due to its various advantages such as simple structure, easy fabrication, good radiation, and ultra-wide band frequency [10]-[11]. 
The fractal geometry shape is used as antenna shapes instead of the euclidean geometries because of its space filling property, also, this fractal geometry is used to obtain the multi-band operation and miniaturization [12]-[14]. The property of space filling in a small area improves the electrical path length of the designed antenna [15]. Generally, the fractal geometry is applied into the patch and it is added in the antenna for designing the fractal antenna which is used to obtain the compact, small side lobe arrays and higher gain aerials [16]-[17]. However, the fractal antennas have different challenges such as radiation pattern enhancement, arbitrary frequency ratio, uniformity of impedance, polarization in multiband and directivity [18]. The Sierpinski fractal antenna is considered as an enormous structure between the fractal antennas. In the design of electromagnetic band-gap, the Sierpinski curve is developed to avoid the simultaneous switching noise over high-speed circuits. This Sierpinski antenna is used to obtain the multiband performance, but the difficulty occurs while designing the antenna for the desired frequency [19]-[20].

The main contributions of this paper are given as follows: The sierpinski carpet fractal monopole antenna (SCFMA) design is developed until two iterations to obtain maximum bandwidth. Therefore, the maximum bandwidth is obtained based on the space filling and self-similar features. Moreover, the reduction in monopole patch size is proposed to minimize area of the overall antenna structure. Here, the patch and the ground are developed using the copper as well as FR4 is used as a substrate with loss tangent of 0.02 and relative permittivity of 4.4 .

The overall organization of the paper are given as follows: The literature survey about the recent fractal shape-based antenna structures is surveyed in section 2. The implementation of SCFMA design up to two iterations along with its dimensions are mentioned in section 3. The results and discussion of the SCFMA design is described in section 4. Finally, the conclusion is made in section 5.

\section{LITERATURE SURVEY}

Thakare [21] analyzed the bandwidth improvement of printed circular planar fractal monopole antenna with and without the proximity coupling. The feed techniques of coal pyrolysis wastewater (CPW) and microstrip line were used to improve the multiband bandwidth in the fractal monopole antenna designed with the coupled proximity ring. Here, the feed technique was used due to the properties of self-similarity in the iterative fractal antenna. This work failed to analyze the gain value of the fractal monopole antenna for all its four iterations.

Gupta and Mathur [22] designed the square shaped UWB fractal antenna along with the right angled isosceles (RIT) Koch in the margin of the patch. The circle shape was developed in the center of the patch to obtain the circular polarization in the resonant frequencies. However, the return loss was improved only when the appropriate matching was done in this fractal antenna.

Varamini et al. [23] presented the microstrip antenna with Sierpinski carpet (MASC) to enhance the matching and bandwidth and the Minkowski fractal was used to maximize the antenna area. The permeability and permittivity were obtained to split ring resonator (i.e., metamaterial) by using the reflection/transmission method. The feature of reconfigurability was achieved by accomplishing the junction in the metamaterial layer. The first antenna was obtained two different resonances such as 3.2 and $4.5 \mathrm{GHz}$ whereas the second antenna was obtained two more resonances such as 3.5 and $5.8 \mathrm{GHz}$ by varying the metamaterial layer. This work analyzed the antenna gain and efficiency only for the indoor application.

Sharma and Sharma [24] presented the two-hybrid fractal slot for designing the microstrip patch antenna (MPA). In this antenna, the Koch curve was used in the first slot as well as the combination of Koch curve with Minkowski was used to develop the second slot. This hybrid fractal slot was designed with the partial ground plane to obtain the wideband applications. The antenna's gain and bandwidth were optimized by varying the length of partial ground plane. However, the gain of the hybrid fractal slot antenna was less in the wideband applications.

Awan et al. [25] developed the ultra-thin flexible patch antenna for Indian summer monsoon (ISM) applications. The utilization of fractal patches was reduced the size up to $30 \%$ according to the typical quadrilateral patch. Next, a rectangular stub was used in the feedline to minimize the harmonics. Hence, this ultra-thin flexible patch antenna was used to obtain compact size, wide bandwidth, and moderate gain. However, the resonating frequency of the antenna was affected because of the stub used in the fractal patch.

Jindal et al. [26] presented the Minkowski and meander curve-based hybrid fractal antenna (MMFHA) for the mobile devices. Here, the mobile devices were used in various communication applications such as mobile ad hoc networks, delay tolerant networks and wireless sensor networks. In this MMFHA, an impedance bandwidth was enhanced by Meander curve as well as multiband was achieved by using the Minkowski curves. However, the impedance was affected with the notch at the ground plane of MMFHA. 


\section{SCFMA DESIGN}

In this SCFMA design, the bandwidth of the antenna is minimized by implementing the sierpinski carpet up to two iterations. The size of monopole patch is optimized for reducing the overall area of antenna design. Initially, this SCFMA design considers the rectangle shape patch and then the square shaped slots are removed in the base case, first iteration and second iteration. The process of this SCFMA design has two major steps which are antenna design configuration and parametric study of the SCFMA design. The antenna design configuration shows the base case, first iteration and second iteration antenna design along with its dimension. The parametric study describes the effect of fractal shapes in microstrip patch. The design process of the SCFMA is described in the following section.

\subsection{Sierpinski fractal antenna}

The design of Sierpinski carpet is generally a plane fractal which is developed by the Wackaw Sierpiński in 1916. The method of partitioning the shape into smaller copies of itself, eliminating one or more replicas and is recursively prolonged to other shapes. In this Sierpinski carpet structure, the middle rectangle is removed in the base case and it is repeated for next two iterations to obtain the wideband frequency range.

\subsubsection{Sierpinski carpet}

In this proposed design, the structure of Sierpinski carpet is initialized with rectangle structure. The rectangle structure is divided into 9 corresponding sub-rectangles in a 3-by-3 grid. The central sub-rectangle removed the base case and this procedure is repeated in first iteration for the remaining sub-rectangles. Additionally, the same procedure is extended in second iteration for all the 8 sub-rectangles of the microstrip antenna. The design of microstrip antenna contains the specific parameters such as resonant frequency antenna width, effective dielectric constant, effective antenna length, length extension, and patch length.

a. Antenna width $(W)$

A practical width $(\mathrm{W})$ is calculated for an effective microstrip antenna which leads to obtain better radiation pattern. The expression to calculate the antenna width is given in the (1).

$$
W=\frac{c}{2 f_{r}} \sqrt{\frac{2}{\varepsilon_{r}+1}}
$$

Where, $c$ is represented as velocity of the light $\left(3 \times 10^{8} \mathrm{~m} / \mathrm{s}\right)$, relative permittivity is represented as $\varepsilon_{r}$ and resonating frequency is represented as $f_{r}$.

b. Effective dielectric constant $\left(\varepsilon_{r}^{e f f}\right)$

The effective dielectric constant of the microstrip antenna is calculated using the following (2).

$$
\varepsilon_{r}^{e f f}=\frac{\varepsilon_{r}+1}{2}+\frac{\varepsilon_{r}-1}{2}\left[1+12(h / W]^{-1 / 2}\right.
$$

c. Antenna length $\left(L_{e f f}\right)$

Generally, the width and length of microstrip antenna is identified by selecting the substrate. The equation (3) shows the effective length of the patch used in the antenna design.

$$
L_{e f f}=\frac{c}{2 \sqrt{\varepsilon_{r}^{e f f}}}\left(\frac{1}{f_{r}}\right)
$$

\section{d. Length extension $(\Delta L)$}

The fields in the patch edge experiences the fringing while designing the antenna. The length of the path is increased by $\Delta L$ on both sides of the patch, because of the fringing fields along the patch length. The extension of the length is given in the (4).

$$
\Delta L=0.412 h\left[\frac{\left(\varepsilon_{r}^{e f f}+0.3\right)\left(\frac{W}{h}+0.264\right)}{\left(\varepsilon_{r}^{e f f}-0.258\right)\left(\frac{W}{h}+0.8\right)}\right]
$$


e. Patch length $(L)$

The actual patch length is determined by using the (5).

$$
L=L_{e f f}-2 \Delta L
$$

The monopole antenna operates at the Wideband frequency but return loss of monopole antenna is low that affects the overall efficiency. Therefore, the design of SCFMA is proposed in monopole antenna to improve the bandwidth.

\subsection{Design configurations}

The structure of Sierpinski carpet fractal antenna is designed from the regular Microstrip patch and it is operated through different iterations to generate the multiband characteristics. The rectangle patch size for the base case is $20 \times 25 \mathrm{~mm}^{2}$ and the middle sub-square slot in the size of $7 \times 7 \mathrm{~mm}^{2}$ is removed as shown in the Figure 1. Next, this Sierpinski carpet fractal antenna is mounted on the substrate with the thickness of $1.6 \mathrm{~mm}$ FR4 substrate and this FR4 substrate has loss tangent $(\delta)$ of 0.02 and relative permittivity $\left(\varepsilon_{r}\right)$ of 4.4. Moreover, the patch and ground are designed by using the copper and the ground plane is created with the size of $30 \times 7 \mathrm{~mm}^{2}$ as shown in Figure 2. This SCFMA antenna uses the microstrip feed line with the width of $2.5 \mathrm{~mm}$ and length of $10 \mathrm{~mm}$ between the patch and ground plane. Moreover, the width and length of feed inset for the microstrip feed are $0.5 \mathrm{~mm}$ and $3 \mathrm{~mm}$ respectively.

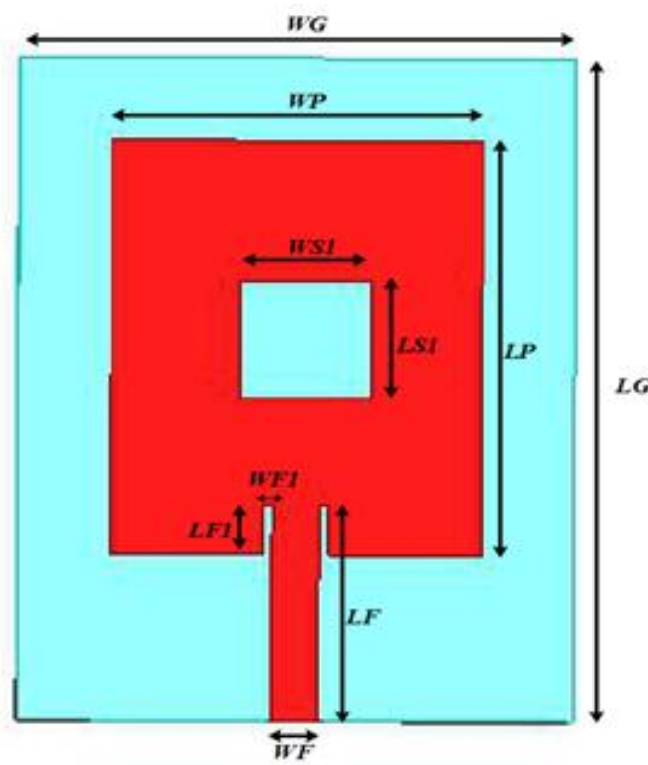

Figure 1. Structure of SCFMA for base case

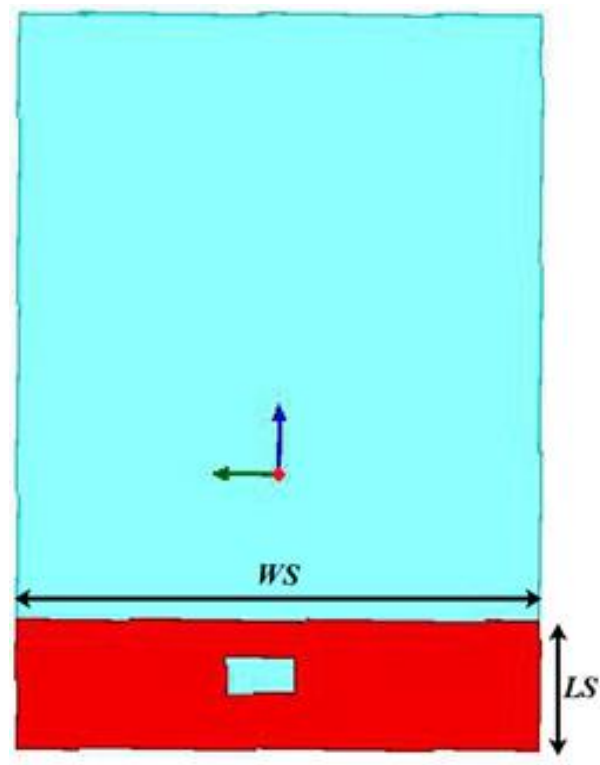

Figure 2. Structure of ground plane

Where, the length and width of the patch are $L P$ and $W P$; the length and width of the ground are $L G$ and $W G$; the length and width of the substrate are $L S$ and $W S$; the length and width of the feed are $L F$ and $W F$; the length and width of the feed inset are $L F I$ and $W F I$; the length and width of the removed slot 1 are $L S 1$ and WS1. In the first iteration of SCFMA, the 8 sub-rectangles of the SCFMA are again divided into 9 sub rectangles. Similar to the base case, the middle sub square slots are removed from all 8 sub-rectangles of patch design. The removed slot has the size of $2 \times 2 \mathrm{~mm}^{2}$ over the SCFMA design which is used to obtain the multi band frequency. The structure of SCFMA for first iteration is shown in Figure 3.

Where, the length and width of the removed rectangle slot 2 are $L S 2$ and WS2. In second iteration of SCFMA, the 8 sub rectangles from the first iteration are again divided into 9 sub rectangles. Similar to the base case, the middle sub squares are removed from all the 8 sub rectangles of patch design. The removed slot has the size of $0.8 \times 0.8 \mathrm{~mm}^{2}$ over the SCFMA design which is used to obtain the multi band frequency. The structure of SCFMA for second iteration is shown in Figure 4. Where, the length and width of the removed rectangle slot 3 are $L S 3$ and $W S 3$. Additionally, the fabricated design of SCFMA antenna is shown in Figure 5. The parameter values of the proposed design are given in Table 1. 


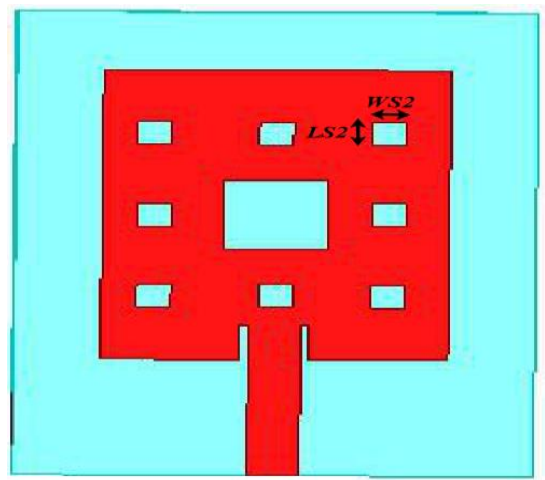

Figure 3. Structure of SCFMA for first iteration

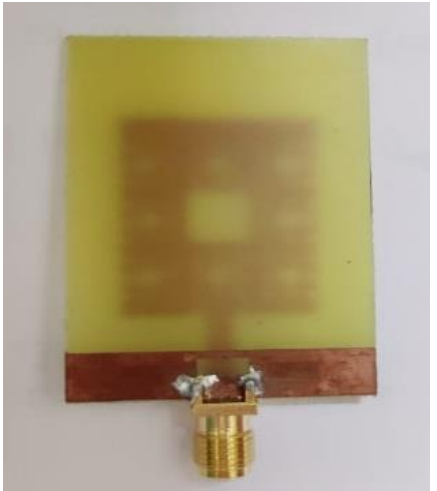

(a)

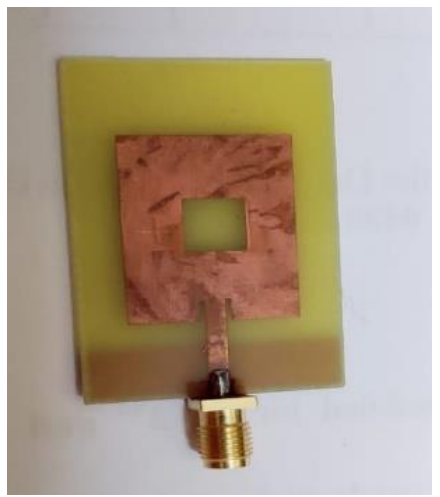

(c)

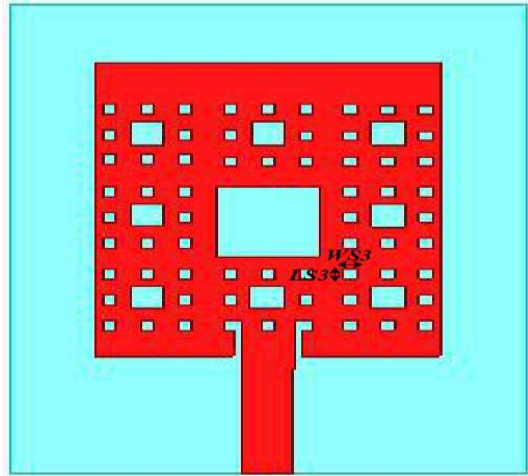

Figure 4. Structure of SCFMA for second iteration

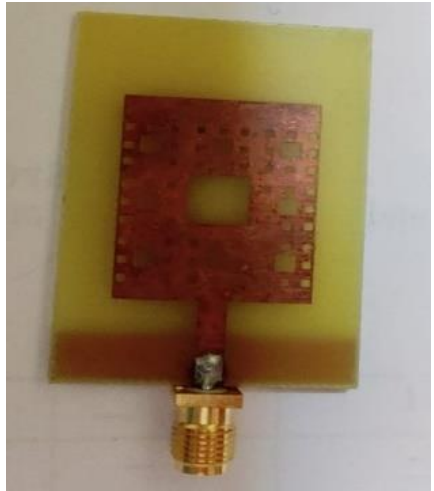

(b)

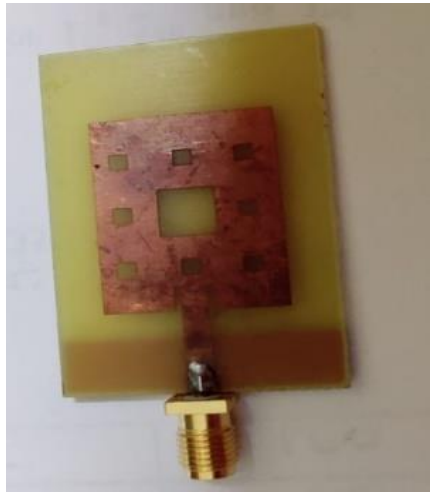

(d)

Figure 5. Fabricated SCFMA antenna: (a) base case, (b) first iteration, (c) second iteration, and (d) back view

Table 1. Parameter values of SCFMA design

\begin{tabular}{cccccc}
\hline Parameter & Value & Parameter & Value & Parameter & Value \\
\hline$L P$ & $25 \mathrm{~mm}$ & $W P$ & $20 \mathrm{~mm}$ & $L G$ & $7 \mathrm{~mm}$ \\
$W G$ & $30 \mathrm{~mm}$ & $L S$ & $45 \mathrm{~mm}$ & $W S$ & $30 \mathrm{~mm}$ \\
$H S$ & $1.6 \mathrm{~mm}$ & $L F$ & $10 \mathrm{~mm}$ & $W F$ & $2.5 \mathrm{~mm}$ \\
$L F I$ & $3 \mathrm{~mm}$ & $W F I$ & $0.5 \mathrm{~mm}$ & $L S 1$ & $7 \mathrm{~mm}$ \\
$W S 1$ & $7 \mathrm{~mm}$ & $L S 2$ & $2 \mathrm{~mm}$ & $W S 2$ & $2 \mathrm{~mm}$ \\
$L S 3$ & $0.8 \mathrm{~mm}$ & $W S 3$ & $0.8 \mathrm{~mm}$ & - & - \\
\hline
\end{tabular}

\subsection{Microstrip line feed}

In microstrip line feed, the conducting strip of microstrip patch is directly connected to the edge of microstrip path as shown in Figure 4. The length and width of the microstrip line feed connected with the 
SCFMA are $10 \mathrm{~mm}$ and $2.5 \mathrm{~mm}$ respectively. The main advantage of using the microstrip line feed is that the feed and microstrip are attached in the same and it is used to design flat structure.

\subsection{Parametric study of the SCFMA design}

The detailed information of the SCFMA design and wideband characteristics are analyzed using this parametric study. The geometrical and electrical properties affect the characteristics of the wideband antenna. The constant parameters in the SCFMA design are the dimensions of patch, ground, substrate, feed, and feed line. In this SCFMA, the fractal structures are developed to obtain the wideband frequencies. Hence, the dissimilarities in the SCFMA design creates the changes in the return loss, voltage standing wave ratio (VSWR) and impedance mismatching properties as shown in Figure 2 to Figure 4. Moreover, the return loss is improved in higher frequencies and weakened lower frequency due to the increment in relative permittivity. The relative permittivity is selected as 4.4 for SCFMA design because of its better return loss in higher frequencies. The higher iterations of Sierpinski Carpet fractal structure are used in the microstrip path antenna for increasing the operating bandwidth of the SCFMA design. Therefore, the SCFMA design obtains UWB frequencies based on the three different designs such as base case, first iteration and second iteration. The electric and magnetic field for the three designs of SCFMA are given in the Figures 6 and 7 respectively.

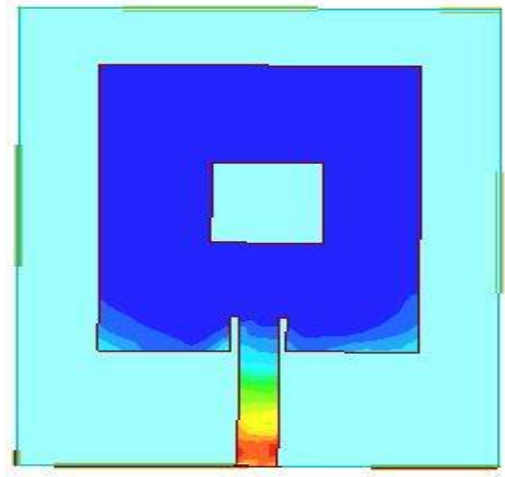

(a)

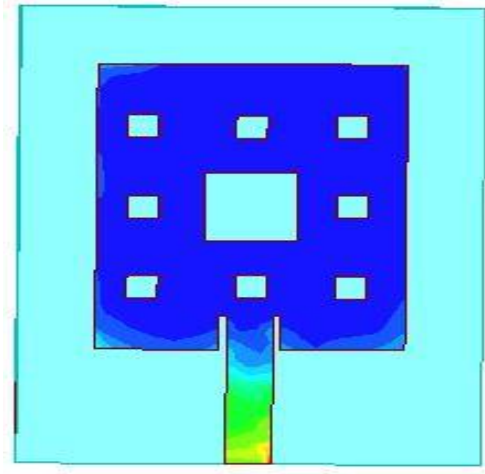

(b)

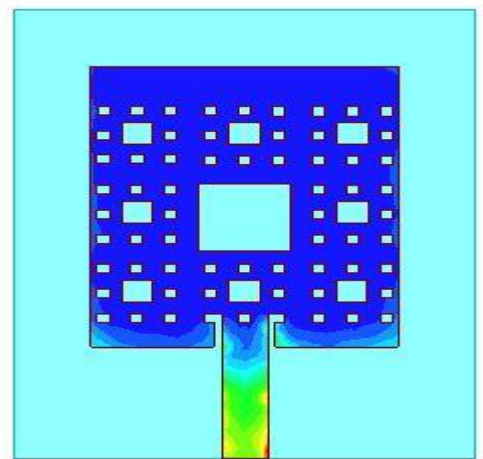

(c)

Figure 6. Electric field for SCFMA design: (a) base case, (b) first iteration, and (c) second iteration

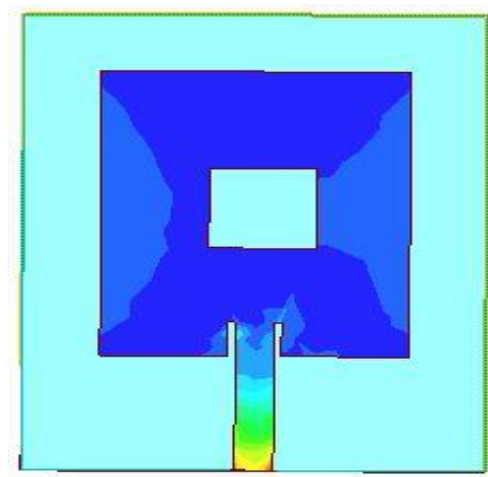

(a)

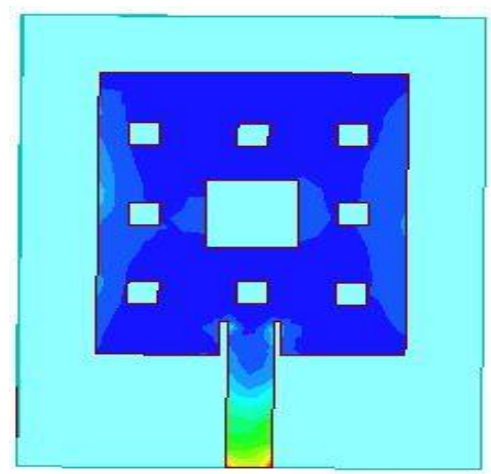

(b)

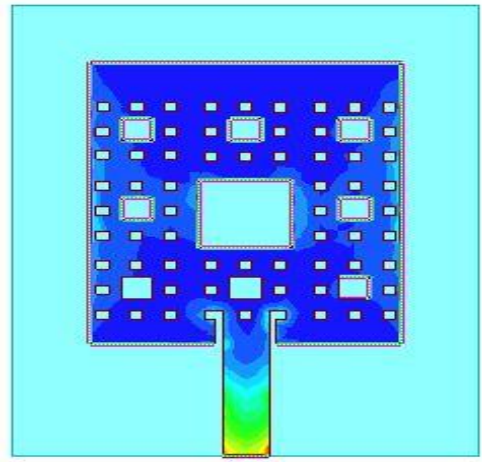

(c)

Figure 7. Magnetic field for SCFMA design: (a) base case, (b) first iteration, and (c) second iteration

\section{RESULTS AND DISCUSSION}

The results and discussion of the proposed SCFMA design is discussed in this section. The proposed SCFMA implementation and simulation are carried out using the high-frequency structure simulator (HFSS) which is operated in a Windows 8 operating system with Intel core i3 processor and 4 GB RAM. This proposed SCFMA design is accomplished in three different designs such as base case, first iteration and second iteration as well as the dimensions of this SCFMA design is given in the Table 1. The performance of 
the SCFMA design is analyzed in terms of return loss, VSWR, radiation pattern and gain. Moreover, the results of the SCFMA design are analyzed using both the simulation and fabrication which are described as follows:

\subsection{Results from simulation}

This section shows the results taken from the simulation using HFSS software. Here, the results are given for SCFMA design with base case, first iteration and second iteration.

\subsubsection{Return loss}

Return loss is the reflection of signal's power when the signal reflection is entered in the transmission line and this return loss is expressed in the (6):

$$
S_{11}=-20 \log |\Gamma|
$$

where the reflection coefficient is represented as $\Gamma$ that is the ratio between incident wave's amplitude and reflected wave's amplitude.

The return loss for the SCFMA at base case, first iteration and second iteration are shown in the Figures 8, 9 and 10 respectively. The resonant frequency of the SCFMA design in base case is $3.4 \mathrm{GHz}$ with a bandwidth of 2.6-4.0 GHz for the return loss value-16.0931 dB. Similarly, the resonant frequency of the SCFMA design in first iteration is $3.2 \mathrm{GHz}$ with a bandwidth of $2.5-4.3 \mathrm{GHz}$ for the return loss value $-21.0295 \mathrm{~dB}$. However, the SCFMA design in second iteration achieves two different resonant frequencies which are $2.8 \mathrm{GHz}$ and $3.8 \mathrm{GHz}$ in the bandwidth of 2.4-4.4 GHz. The return loss of SCFMA design in second iteration obtains two different return loss with respect to the two frequencies $-48.4897 \mathrm{~dB}$ and $-46.7584 \mathrm{~dB}$. Figures 8 to 10 show the return loss of base case which is less when compared to the other designs such as first iteration and second iteration.

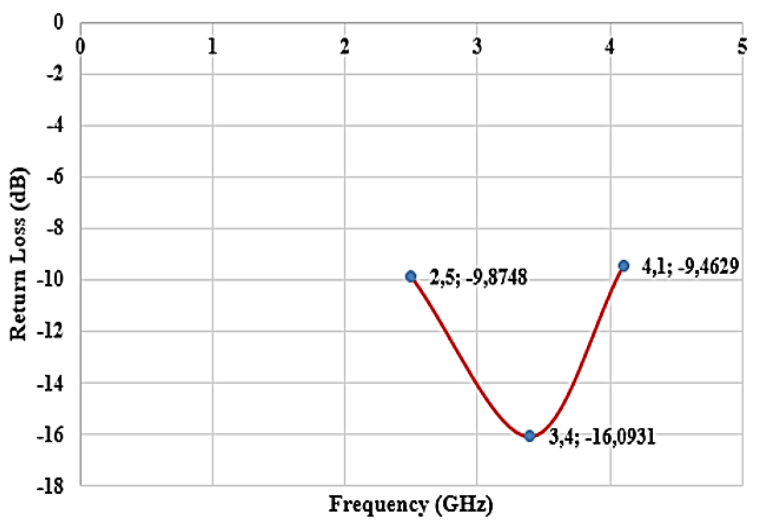

Figure 8. Return loss of SCFMA at base case

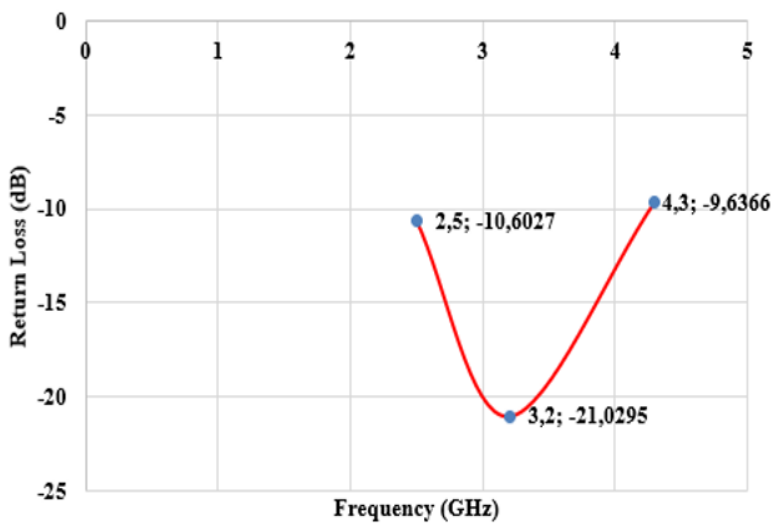

Figure 9. Return loss of SCFMA at first iteration

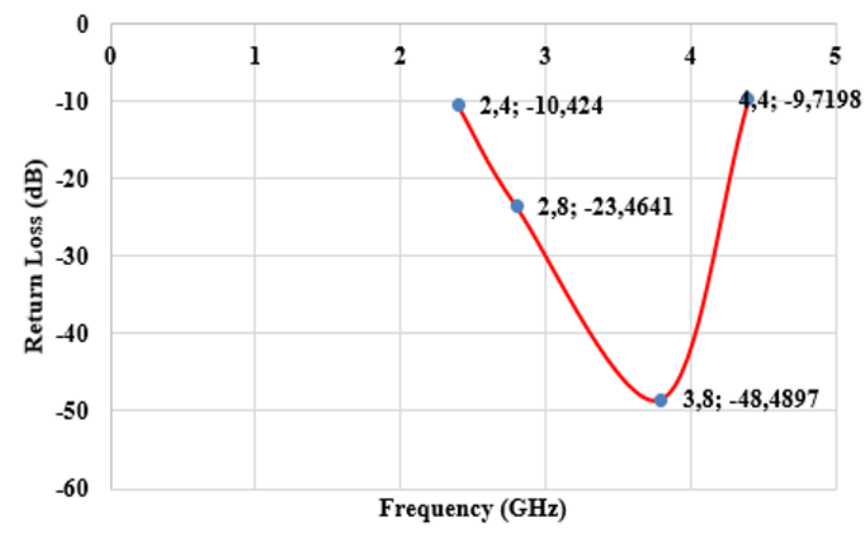

Figure 10. Return loss of SCFMA at second iteration 


\subsubsection{VSWR}

VSWR is the ratio between the maximum voltage $\left(V_{\max }\right)$ and minimum voltage $\left(V_{\min }\right)$ of the antenna which is expressed in the (7).

$$
V S W R=\frac{V_{\max }}{V_{\min }}=\frac{|1+\Gamma|}{|1-\Gamma|}
$$

Figures 11, 12 and 13 shows the VSWR of SCFMA at base case, first iteration and second iteration respectively. The VSWR for the proposed SCFMA in base case and first iteration are 1.5 and 1.8 respectively. However, the SCFMA in second iteration creates two different VSWR which are 1.7 and 1.6. Figure 11 to Figure 13 shows that the VSWR of all 3 designs of SCFMA are less than 2 which shows that it provides better radiation patterns. Hence, the proposed SCFMA obtains better VSWR based on an effective matching between the fractal antenna and microstrip feed line as well as the lesser VSWR improves the frequency and minimizes the loss in the transmitted power.

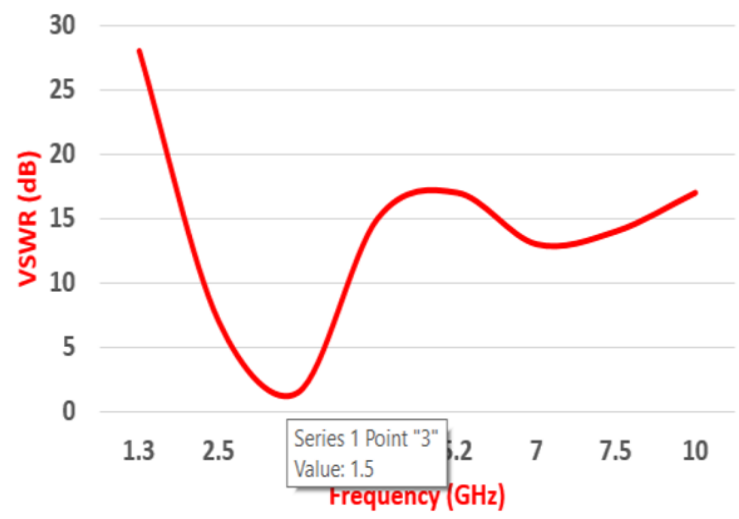

Figure 11. VSWR of SCFMA at base case

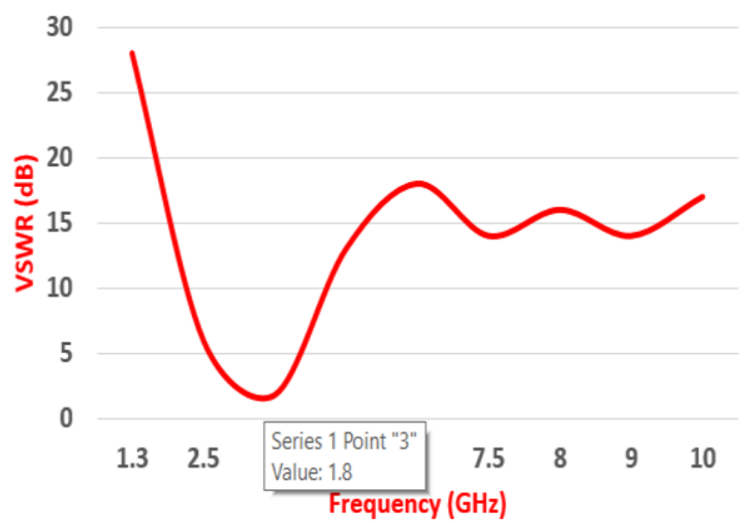

Figure 12. VSWR of SCFMA at first iteration

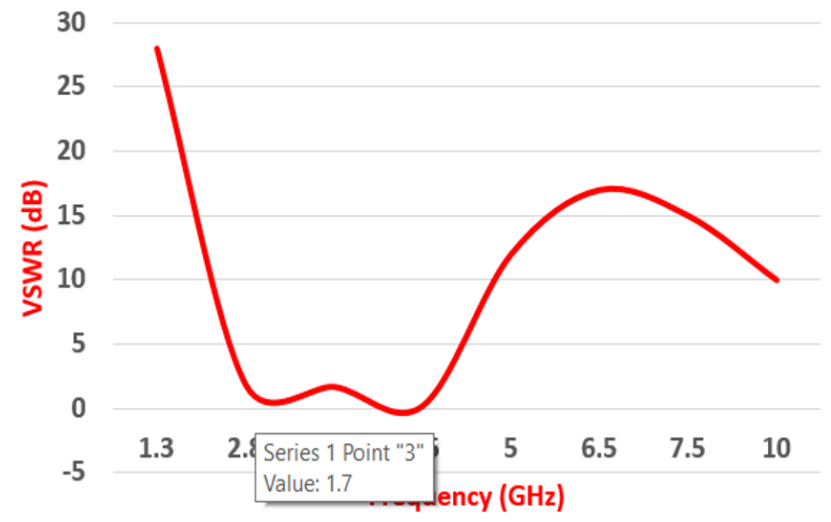

Figure 13. VSWR of SCFMA at second iteration

\subsubsection{Radiation pattern}

The radiation pattern is considered as one of the main parameters in the antenna design that illustrates the ratio of power radiated to input power. This radiation pattern also considers dielectric losses and conduction. The radiation pattern of the SCFMA for base case, first iteration and second iteration are shown in the Figure 14, 15 and 16 respectively. Here, the radiation pattern is calculated by varying the angle $(\theta)$ from $-180^{\circ}$ to $+180^{\circ}$. The radiation pattern presented in the Figures 14,15 and 16 shows that the SCFMA achieves the better radiation pattern in the bandwidth range of 2.6-4.0 GHz, 2.5-4.3 GHZ and 2.4-4.4 GHz respectively. The calculated radiation pattern shows that the SCFMA design obtains a reliable omnidirectional radiation pattern in both the lower and higher frequencies. 


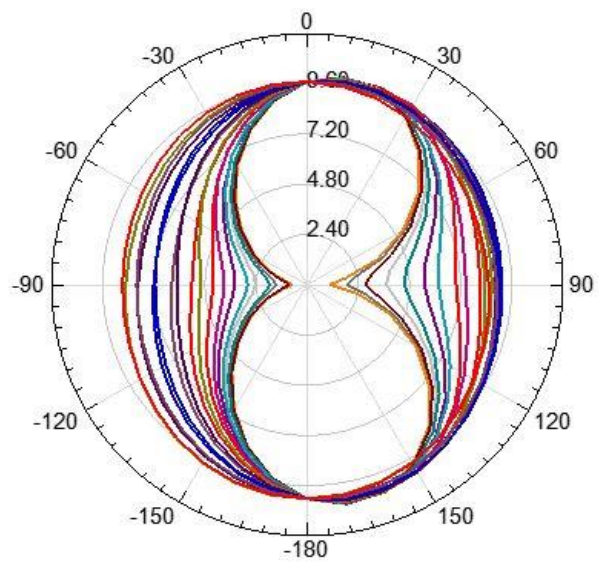

Figure 14. Radiation pattern of SCFMA at base case

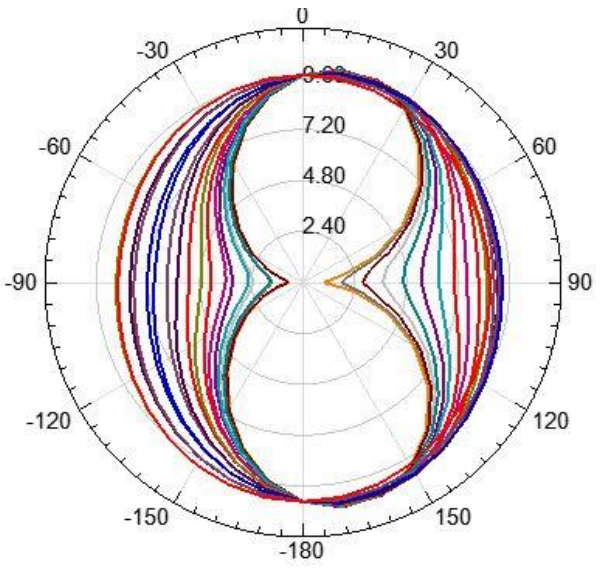

Figure 15. Radiation pattern of SCFMA at first iteration

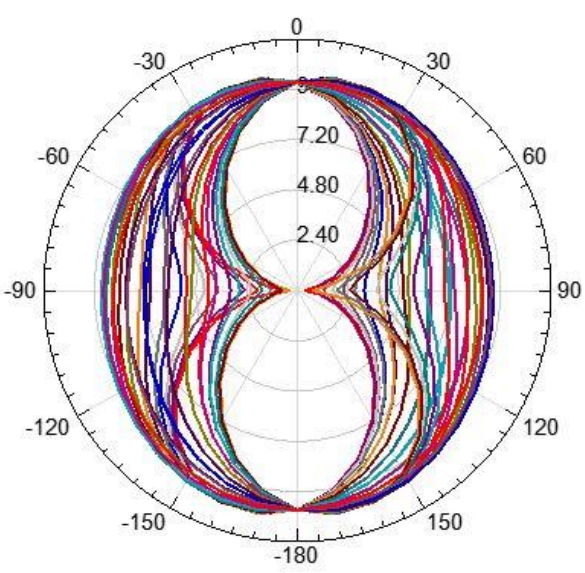

Figure 16. Radiation pattern of SCFMA at second iteration

\subsubsection{Gain}

The ratio between the antenna's output power and antenna's total input power is defined as gain. The input power to the antenna is the total power which includes overall losses power and radiated power. The gain of the antenna is expressed in the (8).

$$
\text { Gain }=\frac{\text { Outputpoweroftheantenna }}{\text { Inputpoweroftheantenna }}
$$

Figures 17, 18 and 19 shows the gain of SCFMA at base case, first iteration and second iteration respectively. Figures 17, 18 and 19 shows that the value of gain are $1.97 \mathrm{~dB}, 1.90 \mathrm{~dB}$ and $2.94 \mathrm{~dB}$ respectively. The antenna with higher gain is used to increase the line of sight path. Hence, the SCFMA design provides higher bandwidth such as $2.6-4.0 \mathrm{GHz}, 2.5-4.3 \mathrm{GHZ}$ and $2.4-4.4 \mathrm{GHz}$ for base case, first iteration and second iteration respectively.

\subsection{Results from fabrication}

Figures 20, 21 and 22 shows the return loss for the fabricated SCFMA at base case, first iteration and second iteration respectively. The return loss for the fabricated SCFMA design at base case and first iteration is $-16.0931 \mathrm{~dB}$ and-21.0295 dB respectively. Additionally, this fabricated SCFMA designed for the second iteration gives two different return losses which are $-48.4897 \mathrm{~dB}$ and $-46.7584 \mathrm{~dB}$. This return loss analysis proves that the fabricated SCFMA design is similar to the simulation results. The results taken from the fabrication design is analyzed in this section. Here, the results are analyzed in terms of return loss, VSWR and radiation pattern. 

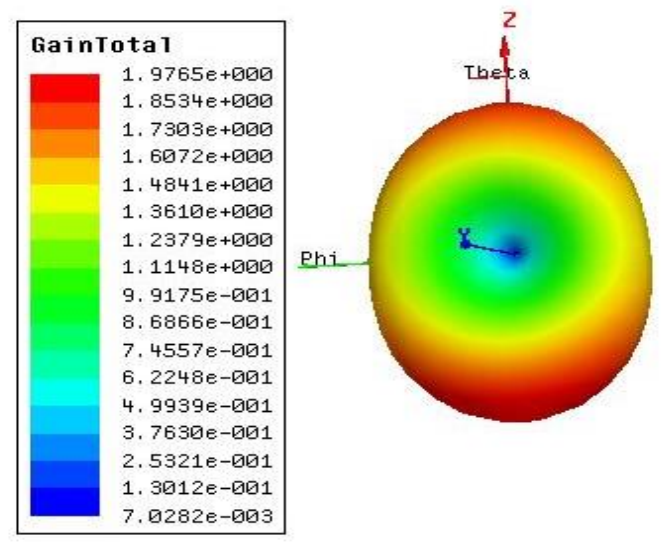

Figure 17. Gain of SCFMA at base case

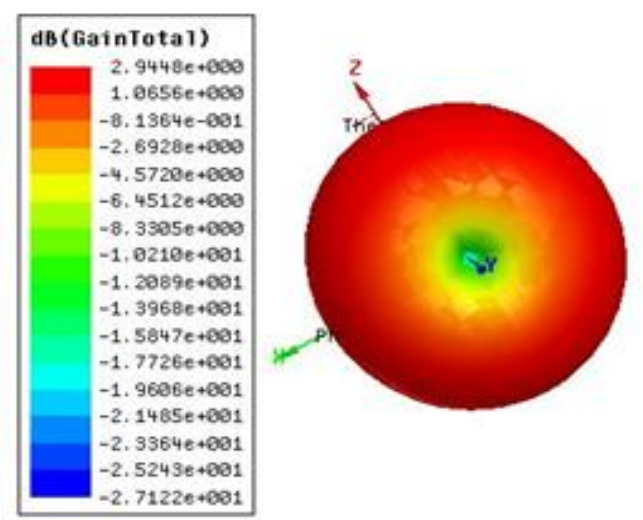

Figure 19. Gain of SCFMA at second iteration

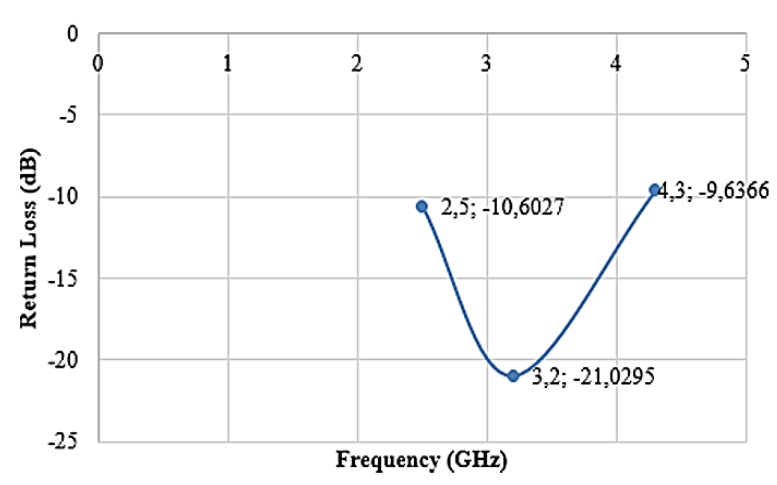

Figure 21. Return loss of fabricated SCFMA at first iteration

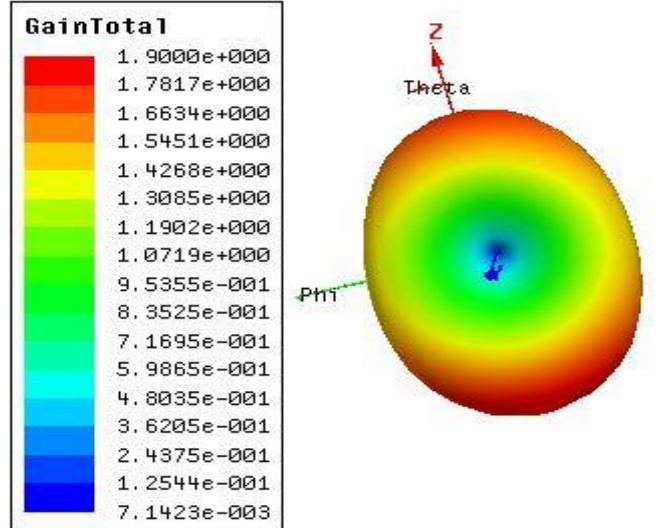

Figure 18. Gain of SCFMA at first iteration

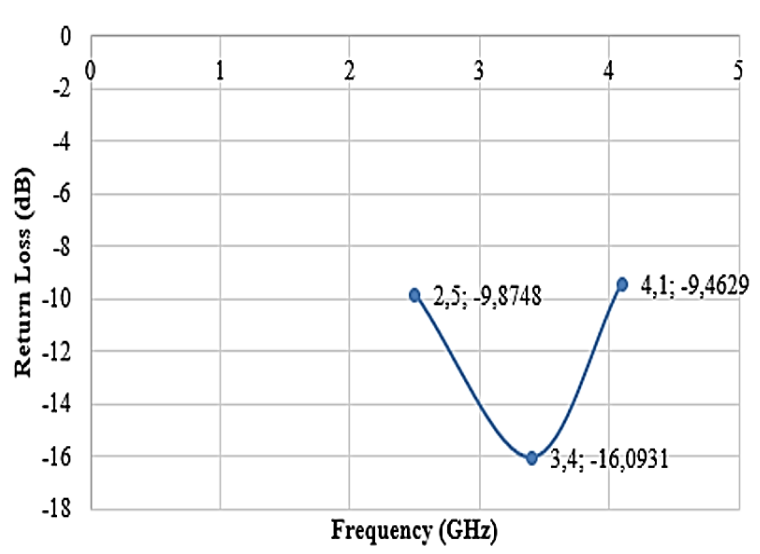

Figure 20. Return loss of fabricated SCFMA at base case

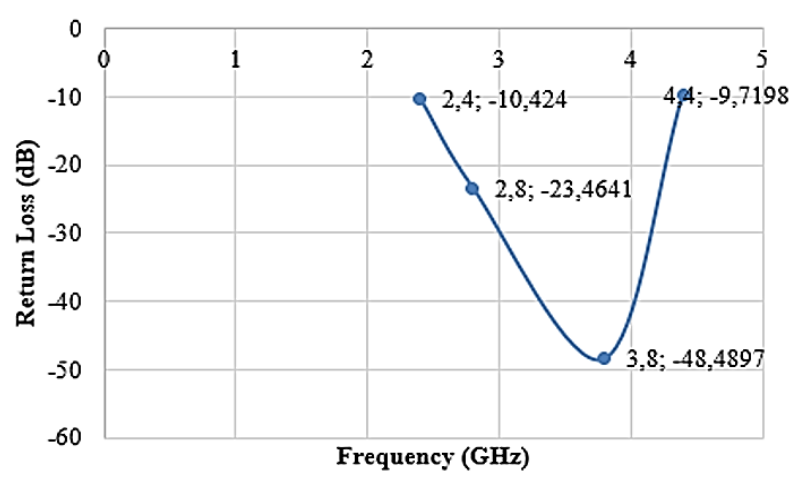

Figure 22. Return loss of fabricated SCFMA at second iteration

The VSWR response of fabricated SCFMA at base case, first iteration and second iteration are shown in the Figures 23, 24 and 25 respectively. The Figures 23 to 25 shows that the VSWR for the base case and first iteration of the fabricated SCFMA are 1.5 and 1.8 respectively. Next, the second iteration of fabricated SCFMA creates two different VSWR ranges such as 1.7 and 1.6. From this VSWR analysis, it concluded that the VSWR is less than 2 for all the three bandwidth values that are 2.6-4.0 GHz, 2.5-4.3 GHz and 2.4-4.4 GHz which helps to avoid the interferences. 


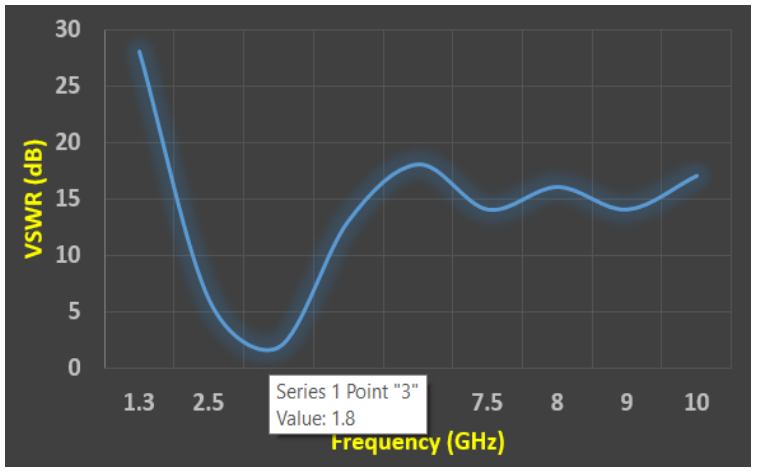

Figure 23. VSWR of fabricated SCFMA at base case

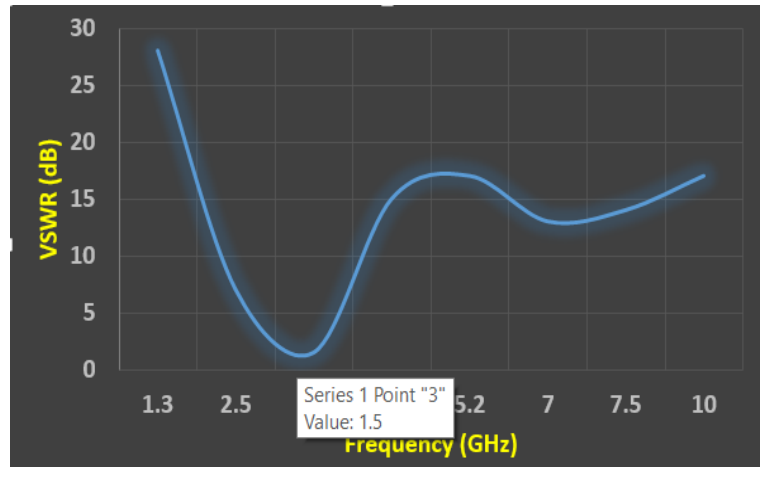

Figure 24. VSWR of fabricated SCFMA at first iteration

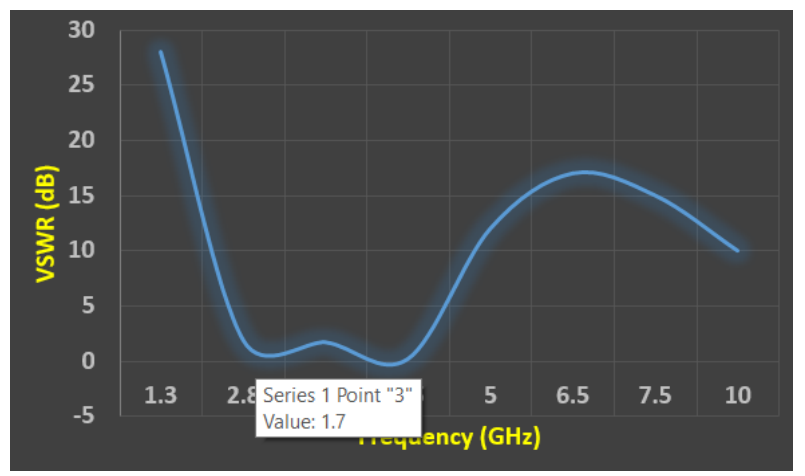

Figure 25. VSWR of fabricated SCFMA at second iteration

Figures 26, 27, 28 and 29 shows the radiation pattern for the resonant frequencies of $3.4 \mathrm{GHz}$, $3.2 \mathrm{GHz}, 2.8 \mathrm{GHz}$ and $3.8 \mathrm{GHz}$ respectively. Here, the Figures 26 and 27 shows the radiation pattern for the base case and first iteration respectively. Next, the Figures 28 and 29 shows the radiation pattern for the second iteration at two different resonant frequency ranges which are $2.8 \mathrm{GHz}$ and $3.8 \mathrm{GHz}$. From the fabrication analysis, it concluded that the proposed SCFMA design provides better results in both the simulation and fabrication designs.

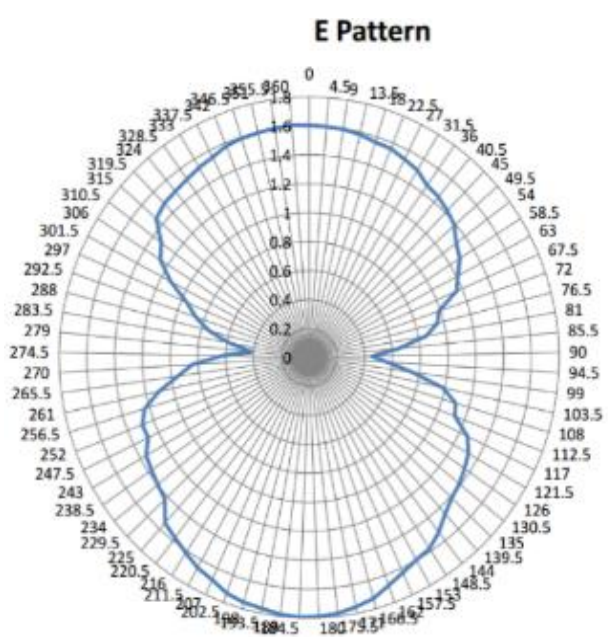

(a)
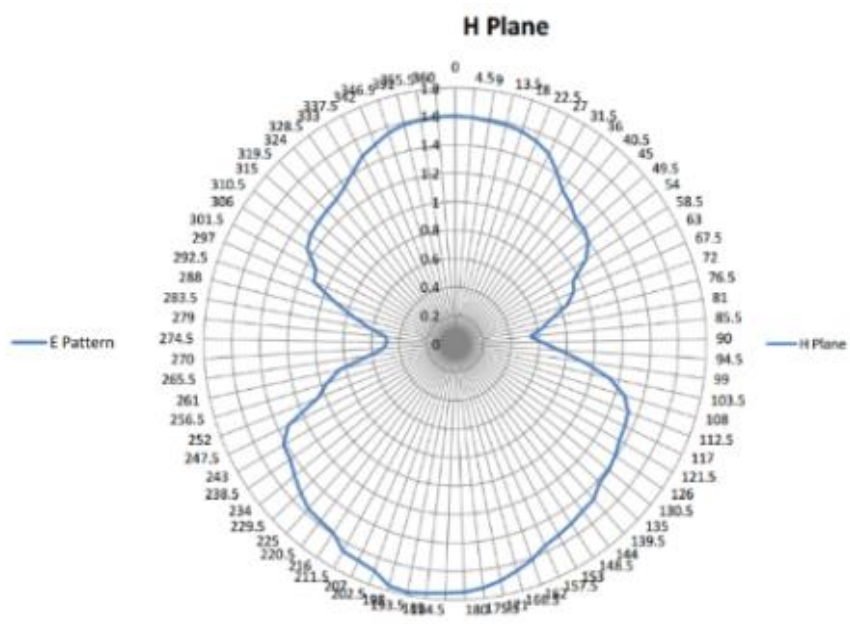

(b)

Figure 26. Radiation pattern of base case-3.4GHz: a) E-Plane, b) H-Plane 


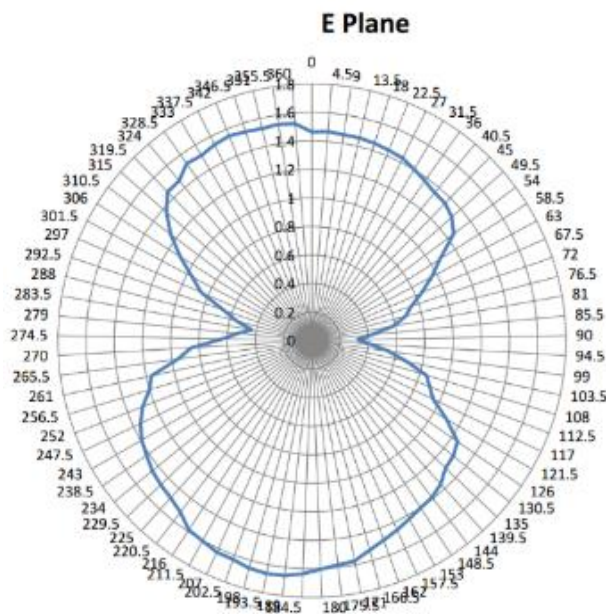

(a)

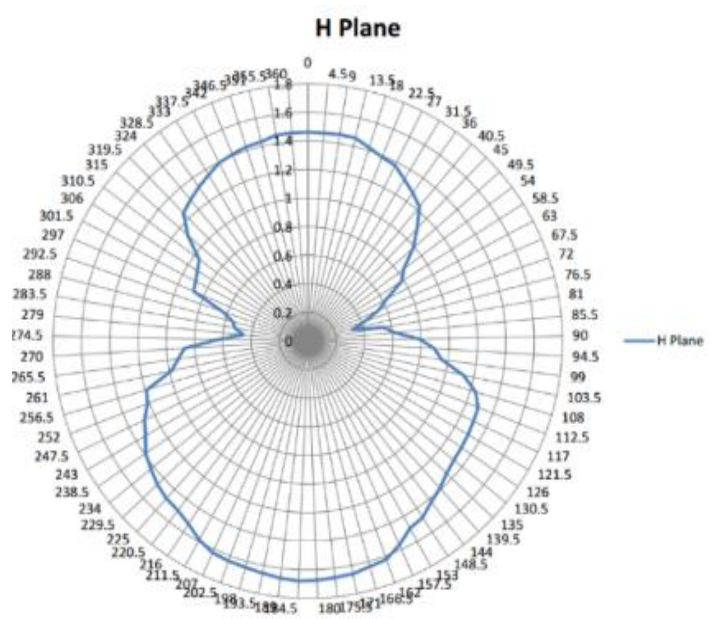

(b)

Figure 27. Radiation pattern of first iteration-3.2 GHz: a) E-Plane, b) H-Plane

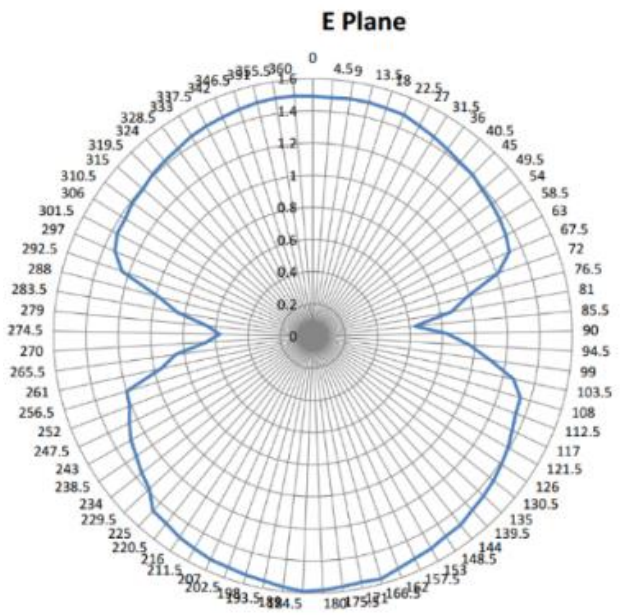

(a)

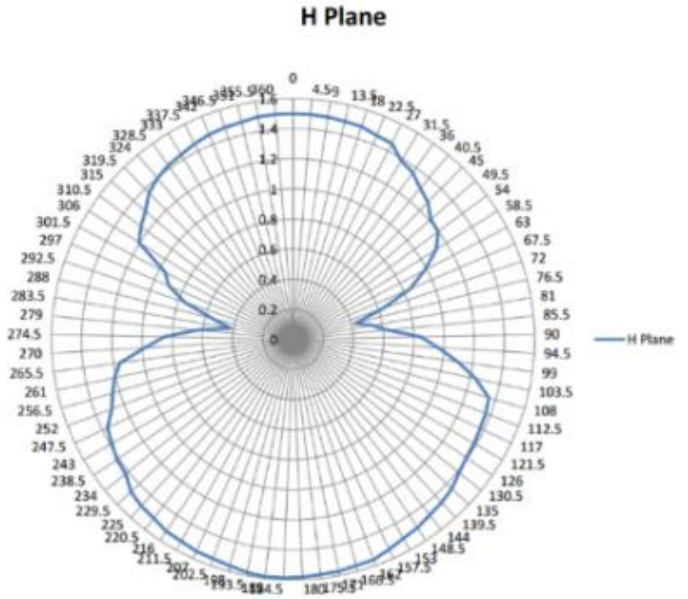

(b)

Figure 28. Radiation pattern of second iteration-2.8 GHz: a) E-Plane, b) H-Plane

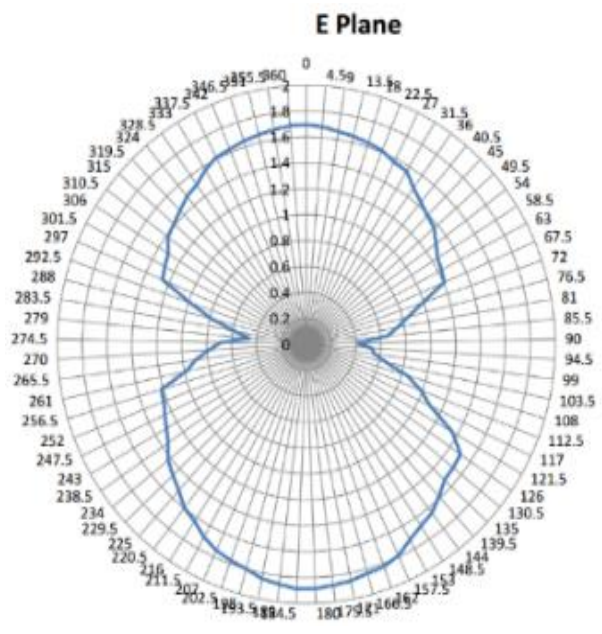

(a)

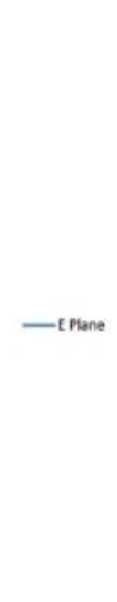

Figure 29. Radiation pattern of second iteration-3.8 GHz: a) E-Plane, b) H-Plane

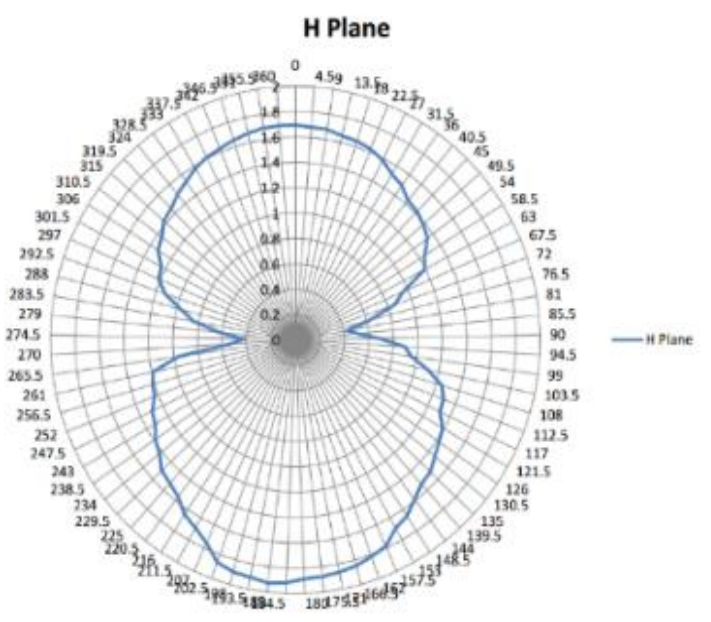

(b) 
Table 2 shows the performance analysis of the SCFMA design for three different iterations. The SCFMA design obtains three different bandwidths for three iterations $2.6-4.0 \mathrm{GHz}, 2.5-4.3 \mathrm{GHz}$ and 2.4-4.4 GHz respectively. Table 3 shows the comparative analysis of the proposed SCFMA with existing fractal antennas such as monopole fractal antenna [21], square patch MPA [22], MASC [23], KochMinkowski hybrid slot based MPA [24], fractal antenna [25] and MMFHA [26]. The SCFMA design achieves lesser size than the existing fractal antennas by optimizing the structure of the monopole patch while designing the fractal structures. Here, the optimized planar structure of SCFMA is designed by using the microstrip line feed. The better selection of microstrip line feeding for the SCFMA design is used to achieve better return loss than the existing fractal antennas.

Table 2. Performance analysis of the SCFMA design

\begin{tabular}{cccccc}
\hline Iteration & Return Loss (-dB) & Bandwidth $(\mathrm{GHz})$ & Resonant frequency $(\mathrm{GHz})$ & VSWR & GAIN $(\mathrm{dB})$ \\
\hline Base & -16.0931 & $2.6-4.0$ & 3.4 & 1.5 & 1.97 \\
Iteration 1 & -21.0295 & $2.5-4.3$ & 3.2 & 1.8 & 1.90 \\
Iteration 2 & $-48.4897 \&-46.7584$ & $2.4-4.4$ & $2.8 \& 3.8$ & $1.7 \& 1.6$ & 2.94 \\
\hline
\end{tabular}

Table 3. Comparison of SCFMA with existing fractal antennas

\begin{tabular}{cccc}
\hline Year & Antenna Design & \multicolumn{2}{c}{ Parameter Analysis } \\
& & Size & Return Loss \\
\hline 2016 & Monopole fractal antenna [21] & $110 \times 115 \mathrm{~mm}^{2}$ & $-18 \mathrm{~dB}$ \\
2017 & Square patch MPA [22] & $60 \times 55 \mathrm{~mm}^{2}$ & $-16.91 \mathrm{~dB}$ \\
2018 & MASC [23] & $40 \times 40 \mathrm{~mm}^{2}$ & $-43 \mathrm{~dB}$ \\
2018 & Koch-Minkowski hybrid slot based MPA [24] & $21.92 \times 28.52 \mathrm{~mm}^{2}$ & $-28 \mathrm{~dB}$ \\
2019 & Fractal antenna [25] & $35 \times 30 \mathrm{~mm}^{2}$ & -15 to $-26 \mathrm{~dB}$ \\
2019 & MMFHA [26] & $35 \times 31 \mathrm{~mm}^{2}$ & $-26 \mathrm{~dB}$ \\
2021 & Proposed Design (SCFMA) & $25 \times 20 \mathrm{~mm}^{2}$ & -16 to -48dB \\
\hline
\end{tabular}

\section{CONCLUSION}

In this paper, the SCFMA is designed using the fractal geometry for UWB applications. The area of the SCFMA design is minimized by optimizing the size of the monopole patch in the dimensions of $20 \times 25 \mathrm{~mm}^{2}$. The bandwidth of the SCFMA design is improved by increasing the number of iterations. The square shaped slots are removed from the rectangle patch during the SCFMA at base case, first iteration and second iteration. Therefore, the self-similar characteristic of the fractal geometry leads to utilization of the SCFMA design in the applications of UWB. The bandwidth obtained in the SCFMA at base case, first iteration and second iteration are 2.6-4.0 GHz, 2.5-4.3 GHZ and 2.4-4.4 GHz respectively. Moreover, the return loss obtained for the SCFMA at base case, first iteration and second iteration are $-16.0931 \mathrm{~dB}$, -21.0295 and $-48.4897 \mathrm{~dB}$ and $-46.7584 \mathrm{~dB}$ respectively. The performance analysis shows that the SCFMA design provides better performance in terms of area. The area of the SCFMA design is $25 \times 20 \mathrm{~mm}^{2}$, which is less when compared to the monopole fractal antenna, square patch MPA, MASC, Koch-Minkowski hybrid slot based MPA, fractal antenna and MMFHA. In the future, an appropriate antenna can be designed to minimize the return loss for all the resonating frequencies.

\section{REFERENCES}

[1] A. Karmakar, P. Chakraborty, U. Banerjee, and A. Saha, "Combined triple band circularly polarised and compact UWB monopole antenna," IET Microwaves, Antennas and Propagation, vol. 13, no. 9, pp. 1306-1311, 2019, doi: 10.1049/iet-map.2018.5459.

[2] S. Mohandoss, R. R. Thipparaju, B. N. B Reddy, S. K. Palaniswamy, and P. Marudappa, "Fractal based ultra-wideband antenna development for wireless personal area communication applications," AEU-International Journal of Electronics and Communications, vol. 93, pp. 95-102, 2018, doi: 10.1016/j.aeue.2018.06.009.

[3] P. Pavithra, A. Sriram, and K. Kalimuthu, "Compact planar ultrawideband MIMO antenna for wireless applications," Int. Journal of Advances in Applied Sciences (IJAAS), vol. 8, no. 3, pp. 243-250, 2019, doi: 10.11591/ijaas.v8.i3.pp243-250.

[4] M. J. Farhan and A. K. Jassim, "Design and analysis of microstrip antenna with zig-zag feeder for wireless communication applications," Bulletin of Electr Eng \& Inf. (BEEI), vol. 10, no. 3, pp. 1388-1394, 2021, doi: 10.11591/eei.v10i3.2122.

[5] N. Sharma, S. S. Bhatia, V. Sharma, and J. S. Sivia, "An octagonal shaped monopole antenna for UWB applications with band notch characteristics," Wireless Personal Communications, vol. 111, pp. 1977-1997, 2020.

[6] A. P. Kumar, D. M. K. Chiatanya, and D. Venkatachari, "Design of high gain dual T-shaped stub antenna for satellite communication," TELKOMNIKA Telecommun Comput El Control, vol. 18, no. 3, 2020, doi: 10.12928/telkomnika.v18i3.14992.

[7] A. Othman, N. I. S. Shaari, A. M. Zobilah, N. A. Shairi and Z. Zakaria, "Design of compact ultra-wideband antenna for microwave medical imaging application," Indonesian Journal of Electrical Engineering and Computer Science (IJEECS), vol. 15, no. 3, pp. 1197-1202, 2019, doi: 10.11591/ijeecs.v15.i3.pp1197-1202.

[8] L. Ray and M. R. Haider, "A compact planar self-affine Sierpinski carpet fractal monopole antenna with band notch characteristics for ultra-wideband communications," Analog Integrated Circuits and Signal Processing, vol. 86, pp. 393-405, 2016 . 
[9] B. S. Taha, and H. M. Marhoon, "Simulation and manufacturing of modified circular monopole microstrip antenna for UWB applications," International Journal Advances Applied Sciences (IJAAS), vol. 10, no. 1, pp. 70-78, 2012, doi: 10.11591/ijaas.v10.i1.pp70-78.

[10] F. B. Zarrabi, Z. Mansouri, N. P. Gandji, and H. Kuhestani, "Triple-notch UWB monopole antenna with fractal Koch and Tshaped stub," AEU-International Journal of Electronics and Communications, vol. 70, no. 1, pp. 64-69, 2016, doi: 10.1016/j.aeue.2015.10.001.

[11] A. Sabah and M. Jasim, “A new patch antenna for ultra-wide band communication applications," Indonesian Journal of Electrical Engineering and Computer Science (IJEECS). vol. 18, no. 2, pp. 848, 2020, doi: 10.11591/ijeecs.v18.i2.pp848-855.

[12] C. Goswami, R. Ghatak, and D. R. Poddar, "Multi-band bisected Hilbert monopole antenna loaded with multiple subwavelength split-ring resonators," IET Microwaves, Antennas and Propagation, vol. 12, no. 10, pp. 1719-1727, 2018, doi: 10.1049/ietmap.2017.1215.

[13] M. O. Al-Dwairi, A. Y. Hindi, M. S. Soliman, and M. F. Aljafari, "A compact UWB monopole antenna with penta band notched characteristics," TELKOMNIKA Telecommunication Computing Electronics and Control, vol. 18, no. 2, pp. 622-630, 2020, doi: 10.12928/telkomnika.v18i2.14542.

[14] M. M. Jawad, N. N. N. Abd Malik, N. A. Murad, M. R. Ahmad, M. R. M. Esa, and Y. M. Hussein, "Design of substrate integrated waveguide with Minkowski-Sierpinski fractal antenna for WBAN applications," Bulletin of Electrical Engineering and Informatics (BEEI), vol. 9, no. 6, pp. 2455-2461, 2020, doi: 10.11591/eei.v9i6.2194

[15] S. Tripathi, A. Mohan, and S. Yadav, "A compact UWB Koch fractal antenna for UWB antenna Array applications," Wireless Personal Communications, vol. 92, pp. 1423-1442, 2017.

[16] M. Gupta and V. Mathur, "A new printed fractal right angled isosceles triangular monopole antenna for ultra-wideband applications,” Egyptian Informatics Journal, vol. 18, no. 1, pp.39-43, 2017, doi: 10.1016/j.eij.2016.06.002.

[17] M. Gupta and V. Mathur, "Wheel shaped modified fractal antenna realization for wireless communications," AEU-International Journal of Electronics and Communications, vol. 79, pp.257-266, 2017, doi: 10.1016/j.aeue.2017.06.017.

[18] D. Li and J. F. Mao, "Coplanar waveguide-fed Koch-like sided Sierpinski hexagonal carpet multifractal monopole antenna," IET Microwaves, Antennas \& Propagation, vol. 8, no. 5, pp. 358-366, 2013, doi: 10.1049/iet-map.2013.0041.

[19] B. S. Dhaliwal, and S. S. Pattnaik, "Performance comparison of bio-inspired optimization algorithms for Sierpinski gasket fractal antenna design," Neural Computing and Applications, vol. 27, no. 3, pp. 585-592, 2016.

[20] P. Iyampalam and I. Ganesan, "Design of sierpinski knopp inspired fractal antenna for public safety applications," Wireless Personal Communications, vol. 114, no. 1, pp. 227-239, 2020.

[21] Y. B. Thakare, "Proximity ring fed multi-band printed mono-pole fractal antenna," International Journal of Antennas (JANT), 2016, doi: 10.5121/jant.2016.2401.

[22] M. Gupta and V. Mathur, "Koch boundary on the square patch microstrip antenna for ultra-wideband applications," Alexandria Engineering Journal, vol. 57, no. 3, pp. 2113-2122, 2018, doi: 10.1016/j.aej.2017.06.005.

[23] G. Varamini, A. Keshtkar, N. Daryasafar, and M. N. Moghadasi, "Microstrip Sierpinski fractal carpet for slot antenna with metamaterial loads for dual-band wireless application," AEU-International Journal of Electronics and Communications, vol. 84, pp.93-99, 2018, doi: 10.1016/j.aeue.2017.11.028.

[24] N. Sharma and V. Sharma, "A design of microstrip patch antenna using hybrid fractal slot for wideband applications," Ain Shams Engineering Journal, vol. 9, no. 4, pp.2491-2497, 2018, doi: 10.1016/j.asej.2017.05.008.

[25] W. A. Awan, N. Hussain, and T. T. Le, "Ultra-thin flexible fractal antenna for $2.45 \mathrm{GHz}$ application with wideband harmonic rejection," AEU-Int. J. of Electronics and Communications, vol. 110, pp. 152851, 2019, doi: 10.1016/j.aeue.2019.152851.

[26] S. Jindal, J. S. Sivia, and H. S. Bindra, "Hybrid fractal antenna using meander and Minkowski curves for wireless applications," Wireless Personal Communications, vol. 109, pp. 1471-1490, 2019.

\section{BIOGRAPHIES OF AUTHORS}

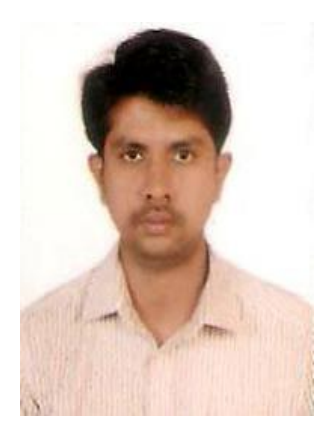

Medhal Bharathraj Kumar (D) 8 SC $\mathrm{P}$ completed his Bachelor of Engineering in Electronics and Communication Engineering in 2009 from Visvesvaraya Technological University (VTU), Belagavi, India, M.Tech in Information technology in 2011, VTU, Belagavi, India. He is presently working as Assistant Professor in the Department of Electronics and communication Engineering at Shri Dharmasthala Manjunstheshwara Institute of Technology, Ujire, Karnataka, India. He has having over 10 years of teaching experience. Presently he is perusing his Ph.D. in the field of antennas, VTU, Belagavi under the guidance of Dr. Praveen J, IQAC Director, Professor and HOD, Department of Electronics and communication Engineering at GM Institute of Technology, He published four UGC approved journals and attended one national conference. His area of interest is microwave and antennas. He has attended 4 workshops related to wireless communication and networks. He can be contacted at email: bharathrajkumar100@gmail.com.

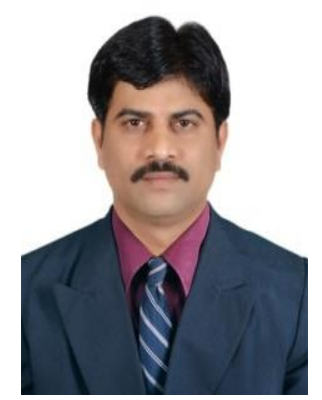

Praveen Jayappa (D) 8D SC P completed his Bachelor of Engineering in Electrical and Electronics Engineering in the year 1999 from Kuvempu University, Karnataka, India, M.Tech in VLSI Design and Embedded System in the year 2004 from Visvesvaraya Technological University (VTU), Karnataka, India, and Ph.D. in Low Power VLSI Design in the year 2017 from Mysore University, Karnataka, India. He is presently working as IQAC Director, Professor and HOD in the Department of Electronics and communication Engineering at GM Institute of Technology, Davangere, Karnataka. India. He has having over 22 years of teaching experience. He is guiding several research scholars and has published more than 70 papers in reputed international journals and conference. His areas of interest are low power VLSI design, frontend and backend VLSI Design. He has delivered invited talks and organized in-house workshops, certificate programs and Notional and International Conference. He can be contacted at email: praveenj_vishruth@yahoo.in. 